\title{
A ENFERMEIRA VIVENCIANDO A FORMULAÇÃO DE CONDUTA DE ENFERMAGEM*
}

Valeria Castillo**

CASTILHO, V. A enfermeira vivenciando a formulaçăo de conduta de enfermagem. Rev. Esc. Enf. USP, v. 26, n. 3, p. $\quad$ - , dez., 1992.

$O$ presente estudo procura desvelar o que ocorre no experienciar das enfermeiras quando formulam condutas de enfermagem, para o tratamento dos problemas dos pacientes, pela utilizaçao do processo de enfermagem. Foi adotada a fenomenologia como vertente metodologica para explicitar a esséncia do fenómeno. Enfermagem.

UNITERMOS: Processo de Enfermagem. Conduta de enfermagem Intervenço de

\section{INTRODUÇĀO}

O processo de enfermagem tem sido apontado como um meio de sistematizar a assistência de enfermagem e, assim, contribuir para o desenvolvimento técnico-científico da profissão.

Esse termo foi introduzido na enfermagem por Orlando, em 1961, e desde então tem recebido várias definiçōes, bem como tem sido constituido de diferentes fases, estando estas vinculadas ou não as teorias de enfermagem, de acordo com as propostas de diversos autores.

Para YURA; WALSH(19), o processo de enfermagem é uma maneira ordeira e sistemática de determinar os problemas do paciente, planejar como resolvé-los, iniciar o planejamento ou designar a outros para implementá-lo e avaliar a extensão em que o plano se mostra eficiente para resolver os problemas identificados.

BULECHEK; McCLOSKEY(2) afirmam que o processo é uma abordagem sistemática de resolução de problemas do paciente com o cumprimento dos cuidados de enfermagem. Para essas autoras o processo traduz a atividade intelectual da enfermeira que anteriormente era vista como intuitiva.

No Brasil, o processo de enfermagem mais conhecido e adotado é o de HORTA(12), que o define como "a dinâmica das ações sistematizadas e inter-relacionadas, visando a assistência do ser humano". Esse processo está vinculado a teoria das Necessidades Humanas Básicas.

- Resumo da Dissertação de Mestrado apresentada à Escola de Enfermagem da USP, 1989, sobre orientação da Dr' Paulina Kurcgant.

* Professora Assistente do Departamento de Orientaçáo Profissional. Escola de Enfermagem. Universidade de São Paulo. Disciplina Administração aplicada à Enfermagem. 
O processo de HORTA(12), fundamenta-se no método científico de resolução de problemas, sendo constituído por 6 fases: histórico de enfermagem, diagnóstico de enfermagem, planejamento assistencial, prescrição, evolução e prognóstico.

Ao adotar esse método para assistir o paciente, a enfermeira: identifica os problemas do paciente; analisa o grau de dependência do paciente em natureza e extensão; determina o plano assistencial global que o paciente deve receber; implementa diariamente o plano assistencial pela prescrição dos cuidados a serem executados para os pacientes; avalia o resultado desses cuidados e estima a capacidade do paciente em atender às suas proprias necessidades.

O processo de enfermagem, proposto por HORTA(12), adotado pelas enfermeiras de algumas instituiçőes de saúde para sistematizar a assistência de enfermagem, vem sofrendo adaptações conforme a realidade de cada local.

Com isso, têm surgido inúmeras publicações nas quais as enfermeiras relatam suas experiências na implantação e desenvolvimento do processo de enfermagem $(5,6,8,14,17,18)$.

Um dos problemas que tem sido apontado pelas enfermeiras, na adoção desse método de trabalho, é a dificuldade no estabelecimento de açóes de enfermagem para a resolução dos problemas do paciente.

Algumas enfermeiras têm evidenciado o fato de que as prescrições de enfermagem geralmente têm se limitado a recomendação de cuidados de rotina, tais como, banho, curativos, controle de sinais vitais, ou simplesmente tem ficado na "observação" $(6,14)$.

Como conseqüência disso têm surgido questionamentos quanto à especificidade dessas ações para a enfermagem e quanto à tomada de decisőes relativas aos problemas observados nos pacientes. As enfermeiras têm formulado para si proprias perguntas como: em quais problemas ou em quais aspectos dos problemas do paciente posso propor ações para resolvê-los?, quais as ações que devem e podem ser prescritas?, como selecionar essas ações?, como avaliar a eficácia dessas ações?

GUTIERREZ(10), afirma que os questionamentos em relação as ações de enfermagem têm se tornado mais complexos porque não se limitam mais aos aspectos operacionais do processo, mas sim às ações concretas adotadas pelo enfermeiro na solução de um problema do paciente. Essas ações, acredita a autora, constituem função específica do enfermeiro.

$\mathrm{Na}$ verdade o que caracteriza o processo de enfermagem é o fato dele ser um método que sistematiza a prática profissional da enfermagem; é o que algumas autoras americanas chamam de "FRAME-WORK", ou seja, a estrutura que a enfermeira utiliza para operacionalizar a assistencia ao paciente. Ao mesmo tempo é um método de resolução de problemas análogo ao método científico de resolução de problemas, que direciona a enfermeira para a busca e escolha de ações a serem adotadas na solução de problemas detectados junto aos pacientes.

Em decorrência desses fatos constatou-se que as enfermeiras têm expressado a necessidade de desenvolver estudos sobre "condutas de enfermagem", testando a aplicabilidade e a eficácia dessas condutas na resolução dos problemas do paciente, facilitando assim a tomada de decisão da enfermeira na prescrição de ações $(6,11,14,16)$. 
Assim, para BENKO; CASTILHO(1), condutas de enfermagem são ações determinadas ou prescritas pelas enfermeiras para a resolução de um problema apresentado pelo paciente.

CAMPBELL(3), denomina conduta como "intervenção de enfermagem" e a define como a "ação singular do enfermeiro para resolver, diminuir ou prevenir as necessidades que são inferidas pelos problemas do paciente.

Para BULECHEK; Mc CLOSKEY(2), que também adotam a denominação de "intervenção de enfermagem", conduta é "a ação autônoma da enfermeira, baseada em regras científicas, que sáo executadas para beneficiar o cliente, seguindo o caminho predito pelo diagnóstico de enfermagem com o estabelecimento de metas a serem alcançadas". Para as autoras, intervenção de enfermagem constitui-se em tratamentos para os diagnósticos de enfermagem.

Na verdade, diagnóstico e intervenção de enfermagem são fases do processo de enfermagem. O diagnóstico de enfermagem foi definido na 9a Conferência da North American Nursing Diagnosis Association (NANDA), em 1990, como sendo "um julgamento clínico das respostas do individuo, da família ou da comunidade aos processos vitais ou aos problemas de saúde atuais ou potenciais, os quais fornecem a base para a seleção das intervençōes de enfermagem, para atingir resultados, pelos quais o enfermeiro é responsável" (Carroll-Johnson apud FARIAS et al(7)).

Embora possamos encontrar na literatura inúmeros trabalhos sobre esse assunto, bem como uma classificação de diagnósticos, eles se encontram em fase de validação e de aperfeiçoamento (FARIAS et al(7)).

Os trabalhos de CAMPEDELLI(4), NUNES; CAMPEDELLI(16), listam as condutas de enfermagem adotada pelas enfermeiras, de um hospital-escola, em relação a alguns problemas observados nos pacientes pelas enfermeiras.

CAMPBELL(3) também, fornece uma lista de condutas ou intervençōes de enfermagem relacionadas aos diagnosticos de enfermagem.

Os trabalhos de CAMPEDELLI(9), NUNES; CAMPEDELLI(16); CAMPBELL (3), porém, não explicam os meios, ou melhor, os processos seguidos pelas enfermeiras para a formação ou escolha dessas intervenções.

GUTIERREZ(10) realizou uma análise do processo de intervenção do enfermeiro num hospital, identificando quatro fases seguidas por eles para a resolução de problemas dos pacientes: "tomada de conhecimento dos problemas dos pacientes", "avaliação dos problemas", "decisão de intervir" e "avaliação da intervenção". A "decisão de intervir" caracteriza-se pela busca e escolha de açōes que possam resolver os problemas dos pacientes.

BULECHEK; McCLOSKEY(2) afirmam que para a escolha das intervenções de enfermagem devem ser observados os seguintes aspectos: característica do diagnóstico de enfermagem; pesquisas básicas associadas com a intervenção; possibilidade de sucesso na implementação da intervenção; aceitação da intervenção pelo cliente e capacitação da enfermeira.

GORDON(9); KELLY(13) apontam para outros aspectos em relação ao estabelecimento do diagnóstico de enfermagem e das intervenções de enfermagem. Consideram a necessidade de serem estudados os processos cognitivos a serem adotados na prática para o estabelecimento dos diagnosticos e intervenções. 
GORDON(9), refere ainda que esse processo cognitivo, que chama de raciocínio clínico, é o que capacita a pessoa a coletar informações pertinentes, interpretar e organizar a informação e chegar a uma definição. Para essa autora o raciocínio clínico têm sua ênfase no elemento de julgamento ou na tomada de decisão, permeada pela inferência, constituindo as operações mentais envolvidas nesse raciocínio.

KELLY(13) afirma que os "processos de julgamento" utilizados pelas enfermeiras quando envolve os processos de enfermagem são ainda pouco explorados. Enfatiza que com a aplicação dos processos de enfermagem tem-se descrito as açóes para a resoluçáo dos problemas dos pacientes mas que tem sido dada pouca atenção às decisões individuais, aos julgamentos ou à forma de raciocínio usados pelas enfermeiras quando determinam um cuidado de enfermagem.

Essa autora ainda questiona o embasamento cientifico que tem sido utilizado na tomada de decisões e o esclarecimento de como as ações de enfermagem vem sendo elaboradas.

Diante do exposto percebe-se que o tema "formação de condutas" é bastante romplexo e muito recentemente foram iniciadas discussões a respeito.

Embora comece a aparecer na literatura propostas de processos a serem seguidos para a formação de condutas (BULECHEK; McCLOSKEY(2)), sabemos muito pouco sobre esse tema, ou seja, como na prática diária as enfermeiras estão desenvolvendo condutas.

\section{OBJETIVO}

O objetivo desta pesquisa foi conhecer e descrever os processos vivenciados pelas enfermeiras na formação de condutas para a resolução dos problemas dos pacientes. E ainda buscar o significado que esses processos têm para as enfermeiras.

\section{O CAMINHO METOdOLógICo} lógica.

No presente estudo adotou-se a fenomenologia como vertente metodo-

Para a análise dos depoimentos dos enfermeiros foram adotados os momentos da análise qualitativa do fenómeno, fundamentado em princípios fenomenologicos propostos por MARTINS; BICUDO(15).

Participaram da pesquisa cinco enfermeiras de diferentes unidades assistenciais de um hospital geral, de ensino, de Săo Paulo, que diariamente vivenciam a situação de "identificar problemas dos pacientes e de propor ações para a resolução dos mesmos", pela utilização de um método de assistência de enfermagem.

Para participar da vivência de cada enfermeiro na formação de condutas para a resolução de problemas dos pacientes realizou-se entrevistas. As entrevistas foram gravadas e depois transcritas em sua totalidade para a análise de seu conteúdo. 


\section{FIGURA 1 - PROCESSOS DE FORMAÇÃO DE CONDUTAS DE ENFERMAGEM DA ENFERMEIRA A}

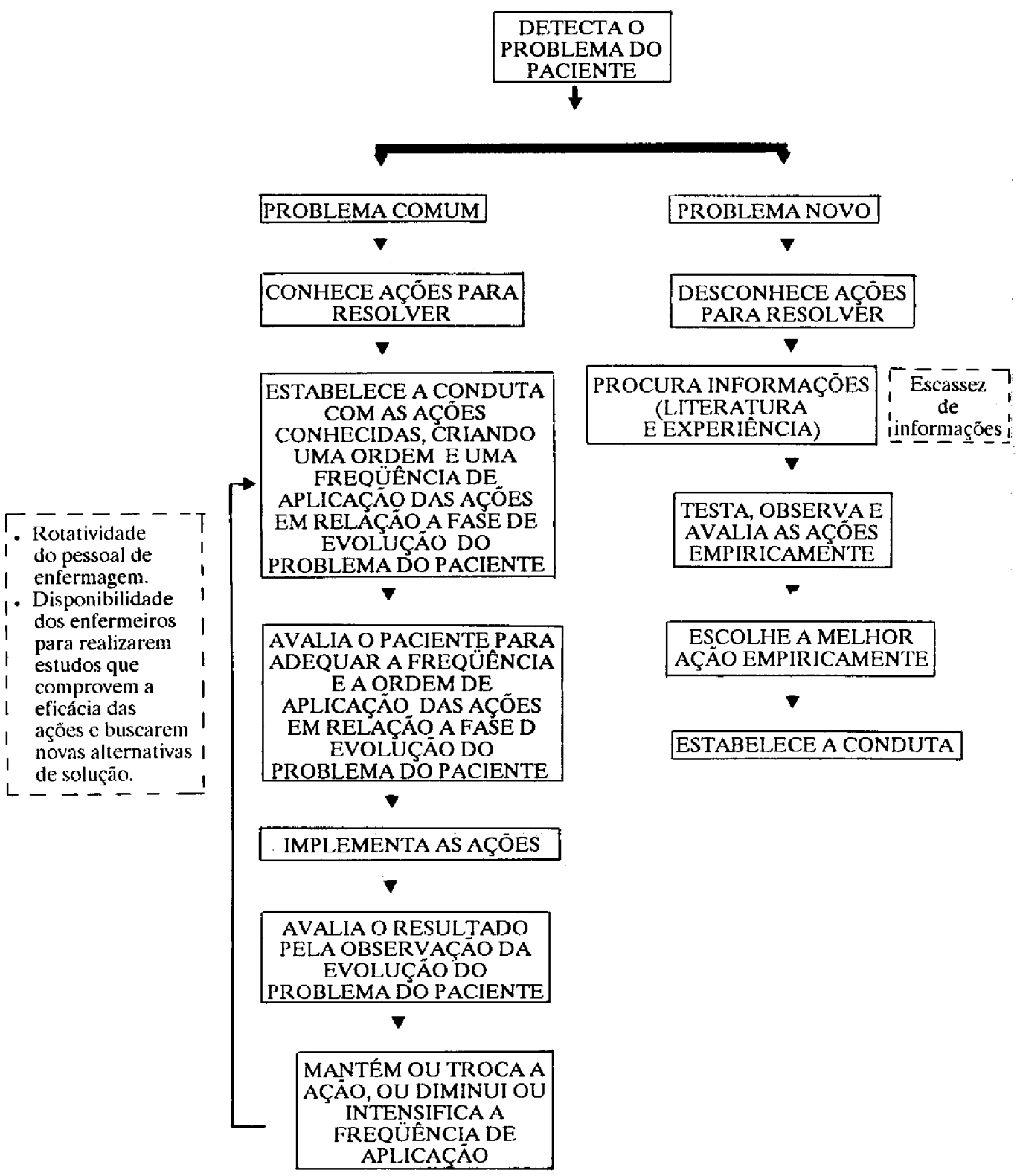

.... . Fatores bloqueadores 
Pela análise dos depoimentos das 5 enfermeiras emergiram os seguintes significados: "sentindo a necessidade de estabelecer condutas", "conceituando", "elaborando", "avaliando", "fatores facilitadores" e "fatores bloqueadores".

Passaremos ao resumo da descrição e interpretação dos depoimentos que contribuiram para o desvelamento da essência do fenómeno formação de condutas de enfermagem.

\section{Descriçáo e interpretaçáo do depoimento da enfermeira $A$}

Enfermeira A, sexo feminino, formada há sete anos, trabalha na Unidade de Berçário e vivencia a aplicação do SAE há cinco anos e meio. Atualmente cursa a faculdade de psicologia.

Durante o seu relato sobre o processo de formação das condutas de enfermagem, utiliza a primeira pessoa do plural, demonstrando que o considera como uma experiência que compartilha com o grupo de enfermeiras com o qual trabalha na Unidade de Berçário. Quando se refere à percepção de fatores bloqueadores do processo, utiliza a primeira pessoa do singular, colocando-se, portanto, individualmente quanto à visão desses fatos.

Fica evidenciado, pela análise dos depoimentos, que a enfermeira A segue dois processos distintos ao elaborar condutas para o tratamento de problemas do paciente. (Fig. 1)

Esses processos são desencadeados pela enfermeira pela observação de um problema do paciente que é por ela percebido como um "problema novo" ou um "problema comum".

Assim, como "problema novo" considera alguma alteração física do paciente para a qual desconhece procedimentos que possam resolvê-lo.

Desencadeia, entâo, um processo de busca de alternativas para a resolução do mesmo, testando-as, até chegar a uma ação que considera eficaz. Essa ação torna-se a conduta adotada para a resolução do problema constituindo-se também em um fator de satisfação de desempenho profissional.

Quanto ao "problema comum" considera que é uma alteração física do paciente, que ocorre de forma freqüente e corriqueira. Para a resolução desse problema há o conhecimento das açōes, uma vez que essas são tradicionalmente adotadas pelas enfermeiras e médicos. Estabelece a conduta com base nessas açōes segundo uma ordem e freqüência adequadas às diferentes fases da evolução do problema do paciente. Durante a implementação da conduta, avalia a evolução do problema e, quando necessário, intensifica ou diminui a freqüência de uma ação. Nessa fase propõe também, em algumas ocasiões, a substituição de uma ação por outra.

Pelas falas da enfermeira A depreende-se que as ações por ela estabelecidas como conduta para a resolução do "problema comum" não são produtos de um processo de reflexão, por ela elaborado, o que gera incerteza quanto à eficácia dos resultados. A conduta, assim estabelecida, é por ela percebida como comum e rotineira e operacionalizada de forma não reflexiva. Como resposta à incerteza 
propõe-se a investigar a eficácia das ações tradicionalmente utilizadas buscando novas soluções.

Em certos momentos do discurso a enfermeira $A$ aponta alguns fatores que percebe como bloqueadores do processo de formação de condutas. Assim, considera como dificuldade, sentida no estabelecimento de uma conduta para um problema novo, a escassez de informações na literatura de enfermagem e médica que julga poderiam auxiliá-la na busca de alternativas.

Já para a resolução de "problema comum" percebe como fatores dificultadores a rotatividade do pessoal de enfermagem e a pouca disponibilidade das enfermeiras para desenvolvimento de estudos sobre condutas.

Pela análise dos depoimentos, pode-se resgatar que para a enfermeira $\mathrm{A}$, o significado de conduta pode ser tanto a ação terapêutica escolhida como os processos por ela trilhados para chegar a ação.

\section{Descriçáo e interpretaçáo do depoimento da enfermeira B}

Enfermeira B, sexo feminino, formada há cinco anos, trabalha na unidade de clínica médica e vivencia a aplicação do SAE nessa unidade há cinco anos.

A formação de condutas é um processo que vem sendo experienciado pela enfermeira $B$, junto com as enfermeiras de sua unidade de trabalho, com o início do funcionamento da clínica médica onde foi implantado o SAE.

Depreende-se, no decorrer do seu relato, que o processo seguido pelas enfermeiras para o estabelecimento das condutas de enfermagem começou quando perceberam que, embora tivessem conhecimento de algumas ações a serem adotadas para a resolução dos problemas dos pacientes, não se sentiam seguras em prescreve-las. Consideravam esse conhecimento insuficiente e, por isso, sentiam necessidade de obterem informaçōes sobre outras alternativas que pudessem ser adotadas. (Fig. 2)

Além disso, não sabiam como prescrever essas ações, isto é, que critérios deveriam seguir para implementá-las. Desconheciam, na prática, a eficácia delas na resolução dos problemas.

Buscaram, então, na literatura, informações sobre as ações e os critérios que deveriam seguir para implementá-las.

Essas ações foram, por elas, prescritas segundo alguns critérios adotados, e conforme a avaliação da eficácia dessas ações na resolutibilidade de um determinado problema, eram adotadas como conduta para esse problema.

Essas condutas estabelecidas continuam sendo utilizadas pelas enfermeiras da clínica médica, mas essa avaliação não tem ocasionado mudanças nessas mesmas condutas.

A enfermeira $B$ percebe a formação de condutas como um processo difícil e empírico, denominando-o de "experimentação empírica" ou "observação empirica".

Afirma que isso se deve à falta de conhecimento científico e a inexperiência das enfermeiras em lidarem com essas questões e tambem, devido ao fato de năo haverem discussões sobre esse assunto, tanto no curso de graduação como na prática profissional. 


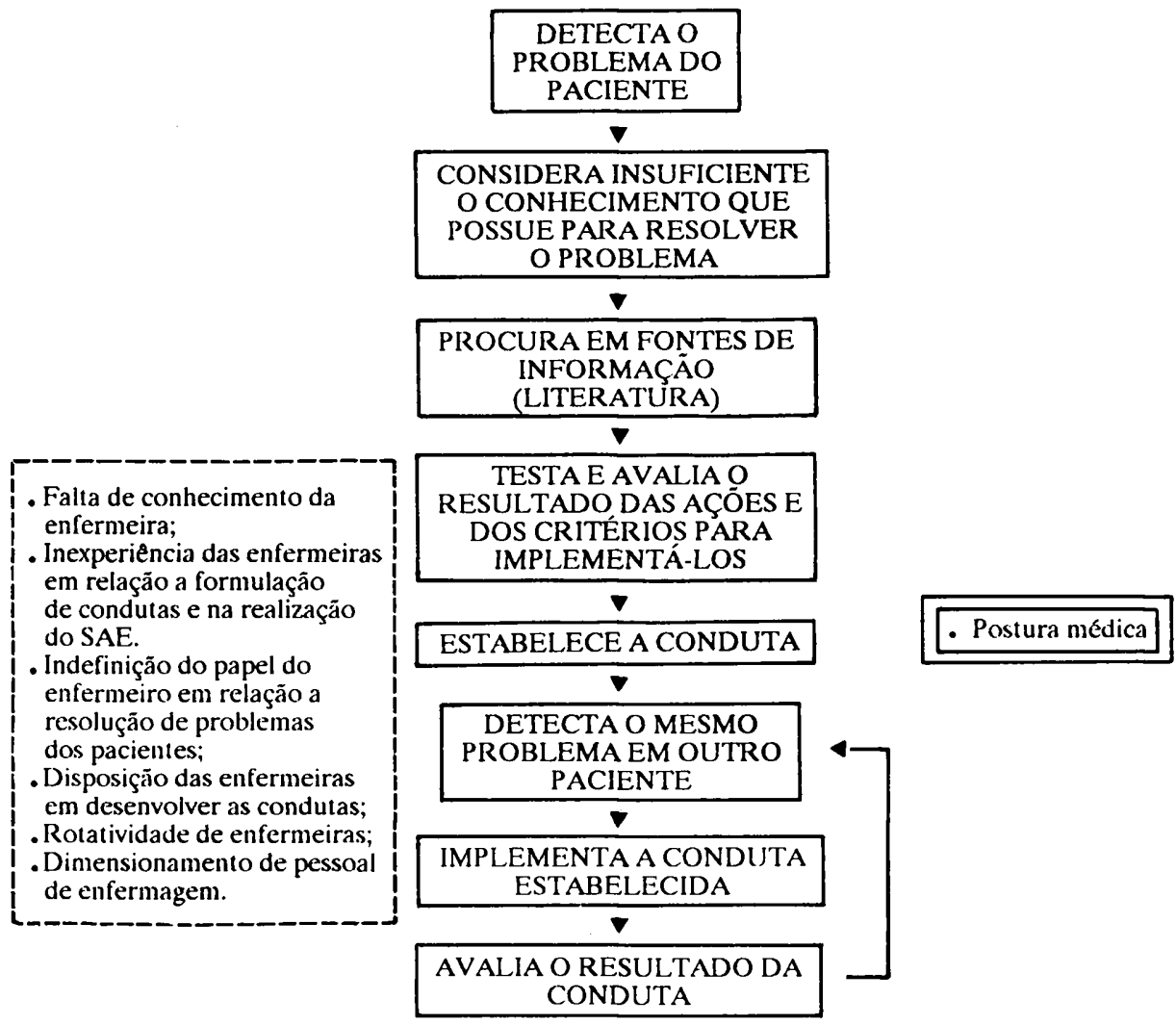

$\begin{array}{ll} & \text { Fatores facilitadores } \\ \ldots-n-\infty & \text { Fatores bloqueadores }\end{array}$

Os fatores que, segundo ela, têm dificultado o processo de formação de condutas e o desenvolvimento de estudos sobre a eficácia dessas açőes: a inexperiência das enfermeiras na utilização de um modelo de sistematização da assistência; a indefiniçăo da área de competência das enfermeiras na resolução dos problemas dos pacientes; o desconhecimento das enfermeiras em como proceder para formular uma conduta; a falta de disposição das enfermeiras para o desenvolvimento desses estudos; a rotatividade das enfermeiras e o dimensionamento de pessoal de enfermagem.

$O$ fator que a enfermeira $B$ tem percebido, como facilitador no processo de desenvolvimento de condutas, é o espaço cedido pelos médicos para que as enfermeiras possam lidar com essas questōes. 
- Falta de motivação das enfermeiras no local atual de trabalho;

- Falta de condições satisfatórias de trabalho;

- Inexperiência das enfermeiras na utilização do processo de enfermagem

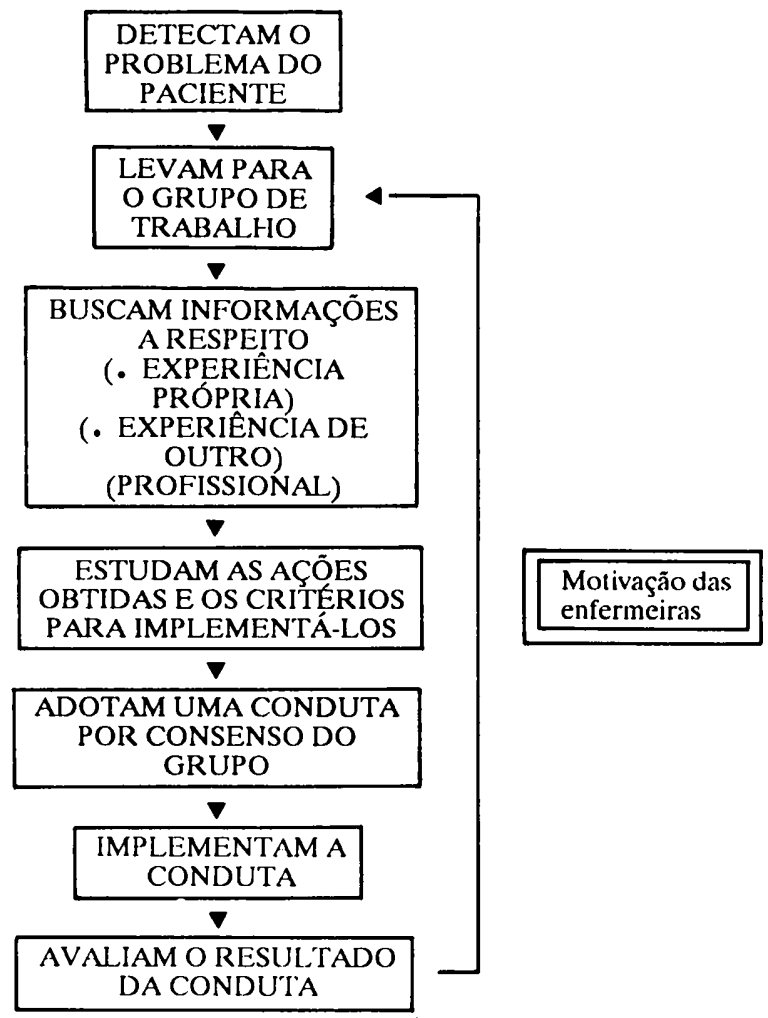

Fatores facilitadores Fatores bloqueadores

\section{Descriçáo e interpretaçáo do depoimento da enfermeira C}

Enfermeira C, sexo feminino, formada há dezessete anos, experiencia a utilizaçăo do SAE no Hospital Universitário há dois anos e meio na Unidade de Emergência.

A formulação de condutas, segundo a enfermeira $C$, não está sendo vivenciada por ela junto às enfermeiras da Unidade de Emergência, mas afirma já ter experienciado esse processo, em outro hospital, onde trabalhou anteriormente. $O$ processo seguido por ela nesse hospital está esquematizado na figura 3.

A enfermeira $C$ relata que tem utilizado as condutas, formuladas no outro 
hospital para a solução de problemas dos pacientes da Unidade de Emergência, onde trabalha atualmente.

Segundo ela, as enfermeiras dessa unidade, apesar de desejarem formular condutas de enfermagem não tem conseguido desenvolvê-las.

Os fatores que percebe como bloqueadores desse processo são: a falta de experiência das enfermeiras na utilização do processo de enfermagem e a desmotivação das enfermeiras devido às condições de trabalho que possuem no Hospital Universitário. Essas condições dificultam a atualização e as discussões sobre esses assuntos.

Considera, em seu relato, que a formulaçăo de condutas só será realizada pelas enfermeiras da Unidade de Emergencia quando perceberem que esse é o caminho para o crescimento profissional, quando as condições de trabalho forem melhoradas e quando aprofundarem seus conhecimentos sobre a prática do processo de enfermagem.

\section{Descriçáo e interpretação do depoimento da enfermeira D}

Enfermeira D, sexo feminino, formada há três anos e vivenciando a aplicação do SAE, na Unidade de Pediatria, há três anos.

Desvela-se pelo relato da enfermeira $D$, que atualmente, na Pediatria, as enfermeiras têm seguido processos individuais para a resoluçăo dos problemas detectados nas crianças, resultando na adoção de diferentes condutas para solucioná-los.

Refere, também, que as enfermeiras acreditam ser necessário uma maneira uniforme de agir para a resolução dos problemas. Para tanto, formaram um grupo de estudos na Pediatria, com o objetivo de levantarem possíveis alternativas, escolherem a mais eficaz, implementarem a conduta adotada de maneira padronizada e avaliarem os resultados dessa ação.

A enfermeira $D$ acredita que a falta de estudos sobre a operacionalização do SAE e, conseqüentemente, estudos sobre condutas, têm dificultado a aquisiçăo, de novos conhecimentos por parte das enfermeiras. Isso tem ocasionado falta de motivaçăo, pois se percebem utilizando o SAE de forma "mecánica", cumprindo apenas mais uma tarefa rotineira.

O processo seguido pela enfermeira $D$ para a resolução dos problemas dos pacientes e o pretendido pelas enfermeiras da Pediatria estão esquematizados na figura 4.

\section{Descriçáo e interpretaçáo do depoimento da enfermeira $\mathbf{E}$}

Enfermeira E, sexo feminino, formada há quatro anos, trabalha na Unidade de Emergência e vivencia a aplicaçăo do SAE há quatro anos.

Depreende-se, pelo relato da enfermeira E, que para ela conduta de enfermagem significa "cuidados básicos" de enfermagem, os quais têm sido tradicionalmente usados pelas enfermeiras para a resolução dos problemas dos pacientes.

Esses cuidados básicos são utilizados pela enfermeira $\mathrm{E}$ para manter ou restabelecer o equilíbrio do paciente, comunicando, ao médico, qualquer alteraçăo observada para que ele possa decidir sobre a terapêtica necessária. 


\section{FIGURA 4 - PROCESSOS DE FORMAÇĀO DE CONDUTA DE ENFERMAGEM DA ENFERMEIRA D}

PROCESSO ADOTADO

\begin{tabular}{|} 
DETECTA O \\
PROBLEMA DO \\
PACIENTE
\end{tabular}

$\nabla$

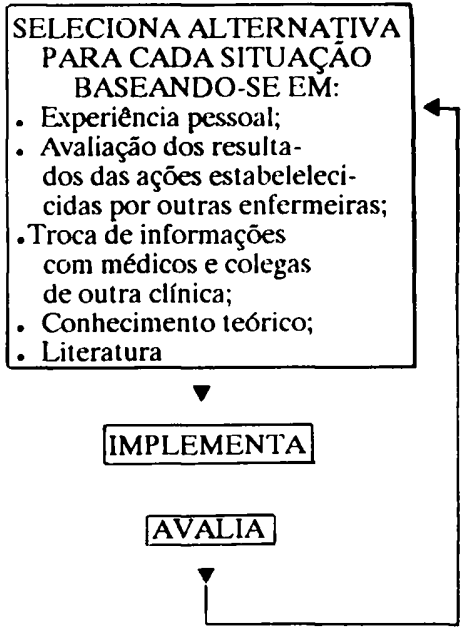

- - -Fatores bloqueadores
PROCESSO QUE ESTÁ SENDO PROPOSTO

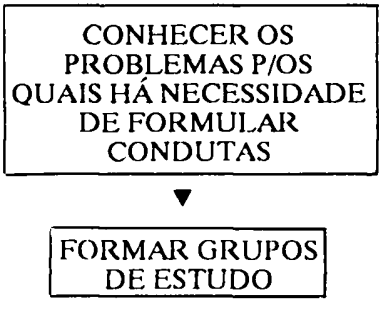

Revela que apesar de conhecer ações de enfermagem para a resolução de alguns problemas percebeu a necessidade de estudá-las, para melhorar a qualidade de suas prescriçóes, quando teve a oportunidade de trabalhar com um grupo de enfermeiras na implantação de uma clínica, onde desenvolveram um programa de estudos sobre $o$ assunto.

Afirma que para as enfermeiras saberem como atuar "melhor" na proposição de ações para a resolução dos problemas dos pacientes têm que haver interesse individual para estudos e pesquisas. $O$ processo seguido por ela para intervir está esquematizado na figura 5. 


\section{FIGURA 5 - PROCESSO DE INTERVENÇÃO DE ENFERMAGEM SEGUIDO PELA ENFERMEIRA E}

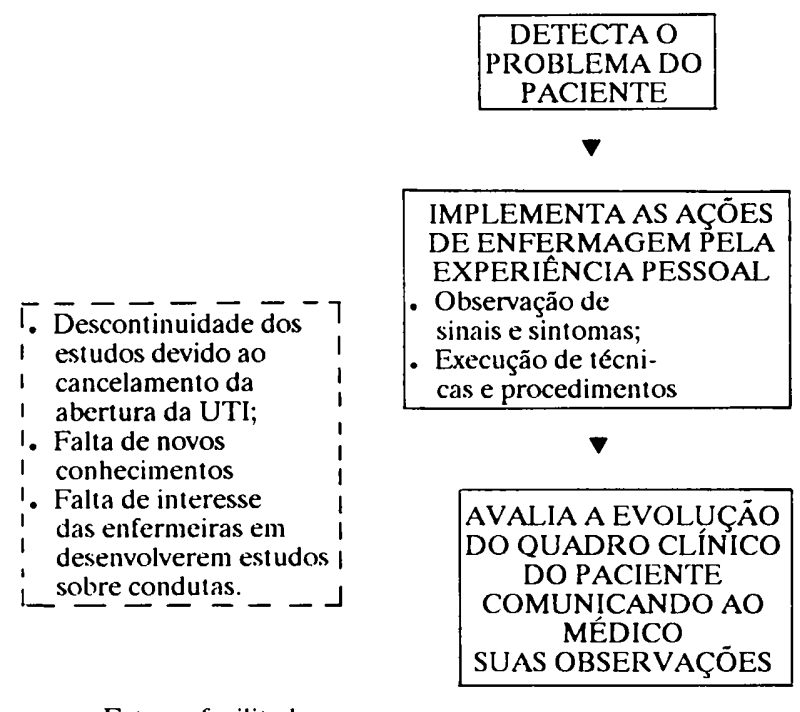

- Formação de grupo de estudo durante o planejamento da UTI,

_... Fatores bloqueadores

\section{COMENTÁRIOS SÍNTESE}

$\mathrm{Na}$ análise dos relatos buscou-se a compreensão da totalidade do vivencial das enfermeiras na elaboração de condutas de enfermagem. Alcançar essa totalidade é tarefa difícil e principalmente torná-la clara numa síntese.

Para a elaboração da síntese foram considerados os pontos convergentes resgatados nos relatos.

Um ponto comum nos cinco relatos foi a necessidade explicitada pelas enfermeiras de formularem condutas de enfermagem, para o tratamento dos problemas detectados nos pacientes, que julgam de sua competência a resolução, com a utilização do processo de enfermagem.

O significado de conduta para as enfermeiras é desvelado como "o conhecimento sobre a forma de atuar para a resolução de um problema".

Para as enfermeiras A, B, C e D o processo de formulaçăo de conduta integra, basicamente, cinco fases: a percepção do problema, o levantamento de informações que as auxiliem na tomada de decisão, a escolha da ação que consideram mais eficaz e a avaliaçåo dos resultados.

Os problemas dos pacientes, que essas enfermeiras percebem como de sua competência, referem-se a alterações físicas externas e visíveis que causam desconforto mas não colocam em risco suas vidas.

Nos relatos das enfermeiras foi desvelado que elas não desenvolvem hipoteses referentes às causas dos problemas dos pacientes e sobre as ações propostas 
para resolvê-los. Não conduzem o raciocínio para realizarem experimentaçóes e observações sistematizadas inerentes ao método científico de resolução de problemas. Esse aspecto ficou evidenciado, principalmente nos relatos das enfermeiras $\mathrm{A}$ e $\mathrm{B}$, quando revelam que não têm conhecimento que as direcionem a um raciocínio e julgamento para decidirem o que fazer na resolução de um problema. Para elas, as enfermeiras ainda estão aprendendo d̀ assistir aos pacientes por meio de um método científico de trabalho.

Outro aspecto desvelado foi que as condutas adotadas por essas enfermeiras são, na verdade, ações tradicionalmente usadas por médicos e enfermeiras no tratamento e prevençăo de determinados problemas.

Portanto, a formulação de condutas não consiste na procura e criaçăo de novas alternativas, mas na escolha da melhor ação dentre as usuais, fundamentada no conhecimento empírico, obtido por elas através de experiências casuais de acerto e erro, a medida que vão prescrevendo essas açóes para os pacientes.

A avaliaçăo das ações propostas para a resolução dos problemas tem sido realizada, pelas enfermeiras, através da observaçăo assistemática da assistência prestada.

Outro ponto comum, desvelado nos cinco relatos, $e$ a necessidade sentida pelas enfermeiras de buscarem novos conhecimentos para a proposiçăo de açôes autónomas e comprovadamente eficazes na resolução dos problemas dos pacientes, atendendo às especificidades dos mesmos. Para isso, apontam a formaçăo de grupos de enfermeiras, para a troca de experiencias, estudos e pesquisas.

Outro ponto de convergéncia nos relatos é o fato das enfermeiras perceberem que a sua capacitação profissional, a filosofia e a estrutura organizacional dos hospitais e os valores pessoais das enfermeiras têm bloqueado a formaçăo e a adoção de condutas de enfermagem.

Nos relatos desvela-se que não há convergéncia em relação aos aspectos que as enfermeiras consideram como facilitadores do processo de formação de condutas. A enfermeira $C$ aponta a motivação das enfermeiras para o estudo das condutas, a enfermeira $\mathrm{E}$ a formação de grupos de estudo.

Esses foram os pontos convergentes por nós depreendidos, mas acreditamos que existe a possibilidade de serem propostas outras interpretaçoes a partir da leitura dos relatos, à medida que a percepção do fenómeno está ligada à interação, à imaginação, à experiência e ds limitaçōes da pesquisadora.

Acreditamos também, que outras interpretaçōes e outros estudos possam propiciar uma maior compreensão sobre o que se passa na experiência das enfermeiras ao adotarem condutas para o tratamento dos problemas dos pacientes.

Esses estudos incentivarão a formaçăo de novos conhecimentos, marcadamente desvelados como necessidade, no vivenciar das enfermeiras e subsidiarăo as discussões sobre modelos a serem propostos para a criação de condutas de enfermagem.

CASTILHO, V. Nurses experiencing the formulation of nursing intervention. Rev. Esc. Enf. USP, v. 26, n 3, p. , dec., 1992.

The present study tries to uncover what happens in the nurses lived experiences when they formulate nursing interventions to solve clients problems, throught the application of nursing process. Phenomenological method was used to make explicit the nature of the phenomenon.

UNITERMS: Nursing process. Nursing interventions. 


\section{REFERENCIAS BIBLIOGRÁFICAS}

1. BENKO, M. A.; CASTILHO, V. Operacionalização de um sistema de assistência de enfermagem. In: CAMPEDELLI, M. C. et al. O processo de enfermagem na prática. Săo Paulo, Ática, 1989, cap. 7, p. 89-111.

2. BULECHEK, G. M.; McCLOSKEY, J. C. Nursing intervention: treatments for nursing diagnosis. Philadelphia, W. B. Saunders, 1985.

3. CAMPBELL, C. Nursing diagnosis and intenvention in nursing practice. New York, John Wiley, 1978.

4. CAMPEDELLI, M. C. Consulta de enfermagem ao binômio mäe-filho: análise das condutas de enfermagem. São Paulo, 1986. 82 p. Tese (Doutorado) - Escola de Enfermagem, Universidade de São Paulo.

5. CAMPEDELLI, M. C. et al. O processo de enfermagem na pratica. São Paulo, Ática, 1989.

6. CRUZ, D. de A. L. M. da et al. Sistematização da assistencia de enfermagem em uma área de recuperaçăo de saúde. Rev. Exc. Enf. USP, v. 21, p. 68-76, 1987. Número especial.

7. FARIAS, J. N. de et al. Diagnóstico de enfermagem: uma abordagem conceitual e prática. João Pessoa, Santa Marta, 1990.

8. FERNANDES, M. A. Processo de enfermagem: aplicação em uma unidade de hospital-escola do interior. Rev. Esc. Enf. USP, v. 21, p. 88-99, 1987. Número especial.

9. GORDON, M. Nursing diagnosis: process and application. 29. New York, McGraw Hill, 1987, cap. 5, p. 151-91: Diagnostic strategies: narrowing the possibilities.

10. GUTIERREZ, M. G. R. de $A$ intervenção do enfermeiro: uma análise a partir da prática. Săo Paulo, 1989. 100 p. Tese (Doutorado) - Escola de Enfermagem, Universidade de São Paulo.

11. HONORATO, S. da S. Implantação e desenvolvimento do processo de enfermagem no hospital-escola. In: CICLO DE DEBATES SOBRE ASSISTÊNCIA DE ENFERMAGEM, 1. Såo Paulo, 1988. Anais. Sāo Paulo, Centro de Estudos de Enfermagem 8 de Agosto do Hospital 9 de Julho, 1989, p. 41-5.

12. HORTA, W. A O processo de enfermagem. Såo Paulo, EPU, 1979.

13. KFLLY, M. A. Nursing diagnosis sourse book: guidelines for clinical application. Norwalk, ApplentonCentury-Crofts, 1985.

14. MARIA, V. L. R. et al. Implantaçåo e desenvolvimento do processo de enfermagem num hospital especializado. In: CICLO DE DEBATES SOBRE ASSISTENCIA DE ENFERMAGEM, 1. Såo Paulo, 1988, Anais. Săo Paulo, Centro de Estudos de Enfermagem 8 de Agosto do Hospital 9 de Julho, 1989, p. 59-70.

15. MARTINS, J.; BICUDO, M. A.V. A pesquisa qualitativa em psicologia: fundamentos e recursos básicos. São Paulo, Moraes, 1989.

16. NUNES, M. I.; CAMPEDELLI, M. C. Consulta de enfermagem em clfnica médica: subsidios para a elaboração de padróes e condutas. Săo Paulo, 1988 (mimeografado).

17. OLIVEIRA, C. Implantaçăo e desenvolvimento do processo de enfermagem na unidade de internação. In: CICLO DE DEBATES SOBRE ASSISTENCIA DE ENFERMAGEM, 1. Săo Paulo, 1988. Anais. São Paulo, Centro de Estudos de Enfermagem 8 de Agosto do Hospital 9 de Julho, 1989, p. 54-8.

18. OSAWA, C. Implantação e desenvolvimento do processo de enfermagem em U.T.I. In: CICLO DE DEBATES SOBRE ASSISTÊNCIA DE ENFERMAGEM, 1. São Paulo, 1988. Anais. São Paulo, Centro de Estudos de Enfermagem 8 de Agosto do Hospital 9 de Julho, 1989, p. 46-53.

19. YURA, H.; WALSH, M. B. The nursing process: assessing, planning, implementing, evaluating. New York, Appleton-Century-Crofts, 1978. 